\title{
In vitro Anti Tubercular Activity and Physicochemical Standardization of Selected Medicinal Plant Extracts
}

\author{
JAYA MARTOLIA* ${ }^{*}$ H. SONI AND FALGUNI TANDEL ${ }^{1}$ \\ Vasu Research Centre (A Division of Vasu Healthcare Pvt. Ltd.), A2/624-625/2, GIDC, Makarpura, Vadodara-390010, \\ ${ }^{1}$ Department of Quality Assurance, Parul Institute of Pharmacy, Parul University, Limda, Waghodiya Vadodara-391760, \\ Gujarat, India
}

Martolia et al.: Standardization and Anti-Tubercular Activity of Plant Extracts

\begin{abstract}
Globally tuberculosis is a major health problem. The main question with the current tuberculosis treatment is adverse effects and drug resistance. The present study aimed to identify safe and effective alternative herbal drugs for the treatment of tuberculosis. This study involves the standardization of selected medicinal plant extracts and in vitro antitubercular activity. Based on the literature survey, four medicinal plant extracts were selected i.e. Glycyrrhiza glabra (Yastimadhu), Piper longum (Pippali), Curcuma longa (Haridra) and Adhatoda vasica (Vasaka). To evaluate the authenticity and quality control aspect, chromatographic fingerprinting and physicochemical analysis were carried out. Quantification of phytomarkers was analyzed by High performance liquid chromatography and in vitro anti-mycobacterial activity was performed by agar well diffusion method on Mycobacterium smegmatis. All necessary physicochemical parameters were performed and found to comply with specified limits. Extracts were authenticated by qualitative High-performance thin layer chromatography fingerprinting in comparison with suitable raw herbs and phytomarkers. Quantification by High performance liquid chromatography showed that Glycyrrhiza glabra contains 10 \% Glycyrrhizin, Piper longum contains 7 \% Piperine, Curcuma longa contains $82.41 \%$ Curcumin and Adhatoda vasica contains $2.3 \%$ Vasicine. In vitro activity of Glycyrrhiza glabra, Piper longum and Curcuma longa showed $20 \mathrm{~mm}, 16 \mathrm{~mm}$ and $14 \mathrm{~mm}$ of maximum Zone of inhibition respectively. Adhatoda vasica did not show any activity against Mycobacterium smegmatis. The present study demonstrates that the selected plant extracts have the potential to inhibit mycobacterial growth. Thus, these standardized herbal extracts could be used in the design and development of a polyherbal formulation for the treatment of primary stage tuberculosis.
\end{abstract}

Key words: Tuberculosis, anti-tubercular activity, standardization, high performance liquid chromatography, medicinal plants

Tuberculosis (TB) is an infectious bacterial disease and is a threat in many regions of the world, especially in developing countries. According to WHO, Tuberculosis is a virulent bacterial disease caused by Mycobacterium tuberculosis, which is most commonly affects the lungs. It is transferred from person to person through droplets. The development of paleopathology and paleoepidemiology in infectious disease has proven the very ancient origin of this disease ${ }^{[1]}$. Every year around 10 million people developed TB disease and 1.3 million deaths from TB. Globally $90 \%$ were adults (aged $\geq 15 \mathrm{y}$ ), two-thirds were in eight countries: India (27\%), China (9\%), Indonesia (8\%), the Philippines (6\%), Pakistan (5\%), Nigeria (4\%), Bangladesh (4\%) and South Africa (3\%) are suffering from $\mathrm{TB}^{[2]}$. Approximately over 50 new Mycobacterium species

*Address for correspondence E-mail: jmartolia@vasuresearch.com

March-April 2021 are reported to cause Mycobacterium infections ${ }^{[3]}$. Currently available treatments have various adverse effects like the time duration of therapy makes patient compliance difficult and such patients become a potent source of drug-resistant strains, another problem of current therapy is that majority of the TB drugs available today are ineffective against pertinacious bacilli, excluding for Rifampicin and Pyrazinamide. Rifampicin is effective against both actively growing and slow metabolizing non-growing bacilli, whereas

This is an open access article distributed under the terms of the Creative Commons Attribution-NonCommercial-ShareAlike 3.0 License, which allows others to remix, tweak, and build upon the work non-commercially, as long as the author is credited and the new creations are licensed under the identical terms

Accepted 16 March 2021 Revised 04 February 2021

Received 07 November 2020 Indian J Pharm Sci 2021;83(2):230-237 
Pyrazinamide is active against semi-dormant nongrowing bacilli. However, there are still pertinacious bacteria that are not killed by currently available TB drugs ${ }^{[4]}$. Three countries India $(24 \%)$, China (13\%), Russian Federation (10\%) accounted for Multi drug resistance (MDR). Extensively drug-resistant (XDR) TB strains are resistant to first-line and second-line anti-tubercular antibiotics. XDR-TB is now present in over 100 countries. Immunosuppressed people are more prone to XDR-TB, especially HIV infected. Thus, there is a need to discover new anti-tubercular drugs that are effective in MDR and XDR tuberculosis.

Approximately $60 \%$ of the world's population still believes in medicinal plants for their primary healthcare. In the Ayurvedic system of medicine, TB is known as 'Rajayakshma'. Several plant species have been reported in Ayurveda for the treatment of TB and its related disorders. But the major concern in Ayurvedic formulations like tablet, capsules are made with plant powders which are not standardized and may have geographical variation which can also affect the potency and stability of finished goods. Since many years, Ayurvedic and herbal medicines has had to compete with modern medicines, which are proven to be quick acting, strong and effective and a recent trend in ayurvedic and herbal manufacturing are reduction in bulk dosage form and enhancement of potency by using standardized plant extracts, patient compliance and acceptability by improving palatability. Hence an effective and alternative standardized antituberculosis herbal drug has to be developed with the help of standardized herbal extracts which is essential to maintain safety and consistent efficacy of the product. For this study, we have selected four medicinal plants extract i.e. Glycyrrhiza glabra (Yastimadhu), Piper longum (Pippali), Curcuma longa (Haridra), Adhatoda vasica (Vasaka) ${ }^{[5-7]}$. Glycyrrhiza glabra (Yastimadhu) acts as an immunomodulator, antitussive, anti-inflammatory, hepatoprotective, antioxidant and antimicrobial ${ }^{[8,9]}$ and one of the studies revealed that Glycyrrhiza glabra (Yastimadhu) acts as an adjuvant in conjunction with anti-TB drugs used as DOTS showed a favorable effect on patients with pulmonary $\mathrm{TB}^{[10]}$. Piperine from Piper longum (Pippali) acts as a bioavailability enhancer and immunomodulatory ${ }^{[11,12]}$. Piperine is one of the ingredient in Risorine Capsule (Rifampicin $200 \mathrm{mg}+\mathrm{INH} 300 \mathrm{mg}+$ Piperine $10 \mathrm{mg}$ ) and studies revealed that it is highly effective in the treatment of drugs vulnerable pulmonary tuberculosis ${ }^{[13]}$.
Curcuma longa (Haridra) have anti-inflammatory, immunomodulatory, antioxidant, free radical scavenging properties ${ }^{[14]}$. The study revealed that it has a hepatoprotective effect against antitubercular drugs induced hepatotoxicity ${ }^{[15]}$, also acts against MTB infection in human macrophages ${ }^{[16,17]}$. Adhatoda vasica (Vasaka) acts as a bronchodilator, antioxidant, hepatoprotective, antimicrobial, antiinflammatory ${ }^{[18,19]}$. Combination of these plants may effectively helpful for the treatment of tuberculosis.

In the present study, the above-described medicinal plant extracts were individually identified; physio chemically standardized and quantified their active constituents by High performance liquid chromatography (HPLC). Further, each standardized plant extracts were used at different concentrations for in vitro anti-mycobacterial activity by using surrogate Mycobacterium smegmatis.

\section{MATERIALS AND METHODS}

\section{Plant extracts and chemicals:}

Glycyrrhiza glabra (Yastimadhu) dry extract, Piper longum (Pippali) dry extract, Curcuma longa (Haridra) dry Extract and Adhatoda vasica (Vasaka) dry extract were obtained from Vasu Healthcare Pvt. Ltd. Vadodara, Gujrat, India. The Mycobacterial Strain i.e. Mycobacterium smegmatis-NCIM 5138/MTCC 6 was procured from the National Collection of Industrial Microorganisms (NCIM) Pune and other AR grade chemicals were procured from Merck, Germany. Lowenstein Jensen Medium slant (LJ Medium) ready to use (Hi-media) and Mueller Hinton Agar (MHA) was used as a media. The medium base was Modified Middle Brooke 7H9 broth with indicator ready to use (Hi-media) and Modified Selective Enrichment (Lyophilized).

\section{HPTLC fingerprinting for identification:}

High-Performance Thin Layer Chromatography (HPTLC) was carried out by CAMAG Linomat

5-Applicator, silica gel 60 F 254 pre-coated aluminum foil plate with layer thickness $0.2 \mathrm{~mm}$ (Merk, Germany). The mobile phase used for Glycyrrhiza glabra (Yastimadhu) ${ }^{[20]}$ was n-butanol: Water: Glacial acetic acid (7:2:1). Mobile phase for Piper longum (Pippali) $^{[21]}$ was Toluene:Diethyl ether: Dioxane (6.25:2.15:1.6), Mobile phase of Curcuma longa (Haridra) ${ }^{[22]}$ was Chloroform:Methanol:Glacial acetic acid (9.4:0.5:0.1) and Mobile phase of Adhatoda vasica 
(Vasaka) $\mathrm{DE}^{[23]}$ was Ethyl acetate:Methanol:Ammonia (8:2:1). Individually applied each sample concerning their powders and standards into the chromate plate and developed the chromate plates in the above mobile phase about $8 \mathrm{~cm}$ from point of application. After removal, dry the plate, then evaluated.

\section{Physicochemical tests:}

Loss on drying (LOD), $\mathrm{pH}$ Value, Water-soluble extractive, Alcohol soluble extractive, Total ash and Acid insoluble ash were performed as per Ayurvedic Pharmacopoeia of India ${ }^{[24]}$.

Quantification of phytomarkers by HPLC: The instrument used for quantification of phytomarkers was Shimadzu make prominence HPLC with Shim Pack Solar column C18 (250 mm $\times 4.6 \mathrm{~mm}$ id, $5 \mu$ particle) and photo diode array (PDA) detector. 'Lab solution' software was used for data collection.

Quantification of glycyrrhizin in Glycyrrhiza glabra (Yastimadhu) ${ }^{[20]}$ : For sample preparation, $500 \mathrm{mg}$ of Glycyrrhiza glabra (Yastimadhu) dry extract was taken in $100 \mathrm{ml}$ of volumetric flask and $100 \mathrm{ml}$ of HPLC grade methanol was added in it, further sonicated it for 15 min \& filtered with $0.22 \mu$ syringe filtration unit. For reference solution, $100 \mathrm{mg}$ of glycyrrhizin was taken in $100 \mathrm{ml}$ of volumetric flask and the volume made up with HPLC grade methanol (1000 ppm), after that sonicated and filtered with a $0.22 \mu$ syringe filtration unit. Sample and reference solution was run in Glacial Acetic acid: Methanol: 0.2 M Ammonium acetate (1:67:33) mobile phase solution and results were detected at UV/PDA $(250 \mathrm{~nm})$.

Quantification of piperine in Piper longum (Pippali) $^{[21]}$ : For sample preparation, 2 gm of Piper longum (Pippali) dry extract was taken in $100 \mathrm{ml}$ of a volumetric flask, $50 \mathrm{ml}$ of HPLC grade methanol was added. After that sonicate it for $3 \mathrm{~min}$ and heated on a boiling water bath for $25 \mathrm{~min}$. Started cooling and diluted it with $100 \mathrm{ml}$ of HPLC grade methanol, further filtration had done with a $0.22 \mu$ syringe filtration unit. For reference solution, $100 \mathrm{mg}$ of piperine had incorporated in $100 \mathrm{ml}$ of volumetric flask and the volume made up with HPLC grade methanol, further took $1 \mathrm{ml}$ of this solution and diluted it with $10 \mathrm{ml}$ HPLC grade methanol (100 ppm), after that sonicate it and filtered with $0.22 \mu$ syringe filtration unit. Sample and reference solution was run in mobile phase solution i.e. A: $0.136 \mathrm{~g}$ of potassium dihydrogen orthophosphate in $900 \mathrm{ml}$ of Demineralised Water (DM water), adjusted to the $\mathrm{pH} 2.5$ with orthophosphoric acid and dilute to $1000 \mathrm{ml}$ with water; B: Acetonitrile and results were detected at UV/PDA (345 $\mathrm{nm})$.

Quantification of curcumin in Curcuma longa (Haridra) $^{[25]}$ : For sample preparation, dissolved 50 mg Curcuma longa (Haridra) dry extract in $50 \mathrm{ml}$ of HPLC grade Acetonitrile, sonicate it for $10 \mathrm{~min}$. and the volume made up to $100 \mathrm{ml}$ by HPLC grade water. Then filter it through a $0.22 \mu$ syringe filtration unit. For reference solution, $10 \mathrm{mg}$ of curcumin was taken into a $100 \mathrm{ml}$ volumetric flask, then approx. $50 \mathrm{ml}$ HPLC grade Acetonitrile was added sonicate it for $10 \mathrm{~min}$ and the volume made up by HPLC grade water, after that filter it through a $0.22 \mu$ syringe filtration unit. Sample and reference solution was run in the mobile phase solution that is A: Acetonitrile (40) B: $2 \%$ Acetic acid (60) and results were detected at UV/PDA (425 nm).

Quantification of vasicine in Adhatoda vasica (Vasaka) ${ }^{[24]}$ : For sample preparation, 2 gm of Adhatoda vasica (Vasaka) dry extract was dissolved in $100 \mathrm{ml}$ of HPLC grade methanol and refluxed it for $30 \mathrm{~min}$ then filtered it through $0.22 \mu$ syringe filtration unit, further $5 \mathrm{ml}$ of this solution was taken and diluted with $10 \mathrm{ml}$ of HPLC grade methanol. For reference solution, 100 $\mathrm{mg}$ of vasicine was taken in $100 \mathrm{ml}$ of volumetric flask and the volume made up with HPLC grade methanol, further $1 \mathrm{ml}$ of this solution was taken and diluted to $10 \mathrm{ml}$ of HPLC grade methanol (100 ppm). $0.1 \%$ Orthophosphoric acid: $100 \%$ Acetonitrile (95:5) was taken as a mobile phase and results were detected at UV/PDA (280 nm).

\section{Invitro anti-tubercular activity of selected plant extracts:}

Culture preparation: Reconstituted the Modified selective enrichment with $1 \mathrm{ml}$ of sterile distilled water. Transferred reconstituted Modified selective enrichment aseptically to the Middle brook 7H9 Broth base. Sample ready to use was taken as Middle brook $7 \mathrm{H} 9$ Broth with Indicator medium. Then incorporated lyophilized culture into the above medium in aseptic condition, mixed well the sample and incubated at $37^{\circ}$ for $48 \mathrm{~h}$. After $2 \mathrm{~d}$, checking the purity of culture by striking a loopful culture from broth on Lowenstein Jensen (LJ) slant. The slant was incubated at $37^{\circ}$ for 48 h. After incubation, observed the light-yellow color colony on LJ medium slant and confirmed it by 
Ziehl-Neelsen stain (ZN) Acid-fast staining under the microscope.

Preparation of bacterial inoculum: Picked one loopful colony of $M$. smegmatis and inoculate into Middle brook $7 \mathrm{H} 9$ broth with indicator medium and used as a bacterial Inoculum.

Sample preparation: All plant samples at different doses were taken individually in a $250 \mathrm{ml}$ Iodometric flask (Table 1). After that methanol and Dimethyl sulfoxide (DMSO) in a ratio of 7:3 had added. Further sonicated all the individual samples for proper mixing then refluxed it on a water bath for $30 \mathrm{~min}$ at $80^{\circ}$. Samples were cooled and centrifuged at maximum rpm for three times. Filtered the supernatants and used it as test samples. Each experiment was performed in duplicate. Sterile Mueller Hinton Agar (MHA) media was cooled up to $55^{\circ}$. After cooling, $15 \mathrm{ml}$ of it was poured by a sterile measuring cylinder into sterile petri plates and then the plate was allowed to solidify on a smooth surface. In the rest of the media, $10 \mu 1$ cultures of bacteria were added and mixed slowly. Then the media was poured on above MHA containing plate. The plate was solidified and then wells were made in MHA plate at a proper distance by sterile borer and labeled. All individual samples at different concentrations were poured in a well.

Solvent (Methanol \& DMSO) was used as a negative control. An experiment was performed in duplicate. When samples were diffused completely in well, all MHA plates were incubated into a Bacteriological incubator at $35^{\circ}-37^{\circ}$ for $48 \mathrm{~h}$ and observed the zone of inhibition.

\section{RESULTS AND DISCUSSION}

Chromatographic fingerprinting of herbal dry extracts was used for the authenticity and quality control of herbal medicines. Retention factor (Rf) Value of Glycyrrhizin Standard, Glycyrrhiza glabra dry extracts and Glycyrrhiza glabra powder were found to be 0.28 (fig.1). Physico-chemical parameters of Glycyrrhiza glabra dry extract are detailed in Table 2. Glycyrrhiza glabra dry extract contains $10 \%$ of Glycyrrhizin. Retention time (RT) of Glycyrrhiza glabra dry extract was 10.150 and Glycyrrhizin standard was 10.281 which are shown in fig. 2 and fig. 3. Rf Value of Piperine Standard, Piper longum dry extract \& Piper longum powder were found to be 0.65 (fig. 4). Hence confirm the presence of Piperine. Physico-chemical parameters of Piper longum dry extract are detailed in Table 3. Piper longum dry extract contains $7 \%$ of Piperine active content. Retention time (RT) of Piper longum dry extract is 25.879 and Piperine standard is 25.867 which are presented in fig. 5 and fig. 6. Rf Value of Curcumin Std., Curcuma longa dry extract and Curcumin powder were found to be 0.73 (fig.7). Physicochemical parameters of Curcuma longa dry extract are detailed in Table 4. Curcuma longa dry extract contains $82.41 \%$ of Curcumin. Retention time (RT) of Curcuma longa dry extract was 38.549 and Curcumin std. was

\section{TABLE 1: SAMPLE PREPARATION AT DIFFERENT} DOSES

\begin{tabular}{|c|c|}
\hline Plant Extracts & Doses \\
\hline $\begin{array}{l}\text { Glycyrrhiza glabra } \\
\text { (Yastimadhu) DE }\end{array}$ & $\begin{array}{c}40 \mathrm{mg}, 60 \mathrm{mg}, 80 \mathrm{mg}, 100 \mathrm{mg} \\
\text { and } 120 \mathrm{mg}\end{array}$ \\
\hline Piper longum (Pippali) DE & $\begin{array}{c}30 \mathrm{mg}, 50 \mathrm{mg}, 70 \mathrm{mg}, 90 \mathrm{mg} \\
\text { and } 110 \mathrm{mg}\end{array}$ \\
\hline Curcuma longa (Haridra) DE & $\begin{array}{c}10 \mathrm{mg}, 20 \mathrm{mg}, 30 \mathrm{mg}, 40 \mathrm{mg} \\
\text { and } 50 \mathrm{mg}\end{array}$ \\
\hline Adhatoda vasica (Vasaka) DE & $10 \mathrm{mg}, 30 \mathrm{mg}, 50 \mathrm{mg}$ and 70 \\
\hline
\end{tabular}

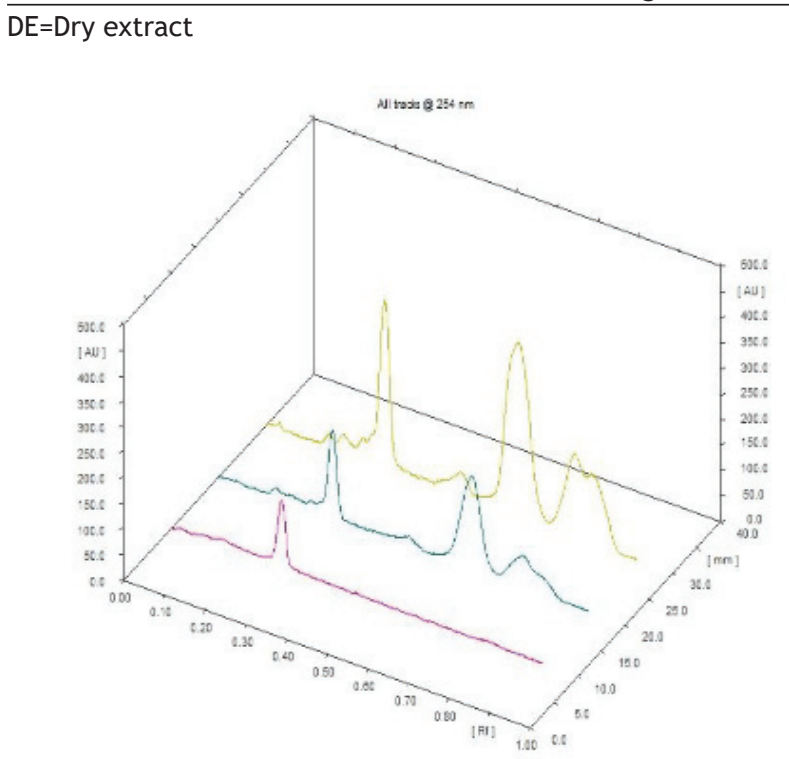

Fig. 1: HPTLC Fingerprinting of Glycyrrizin, Glycyrrhiza glabra DE and Glycyrrhiza glabra powder at $254 \mathrm{~nm}$

TABLE 2: PHYSICOCHEMICAL EVALUATION OF Glycyrrhiza glabra DE

\begin{tabular}{lc}
\hline Parameters & Results \\
\hline Description & $\begin{array}{c}\text { Brown color powder with a } \\
\text { characteristic taste }\end{array}$ \\
LOD & $5.18 \%$ \\
pH (1 \% solution) & 5.37 \\
Water Soluble extractive & $93.98 \%$ \\
Alcohol Soluble extractive & $40.38 \%$ \\
Total Ash & $5.99 \%$ \\
Acid insoluble ash & $4.09 \%$ \\
$\%$ Active of Glycyrrhizin by & $10.0 \%$ \\
HPLC &
\end{tabular}

$\mathrm{DE}=$ Dry extract; $\mathrm{LOD}=$ Loss on drying; HPLC=High performance liquid chromatography 


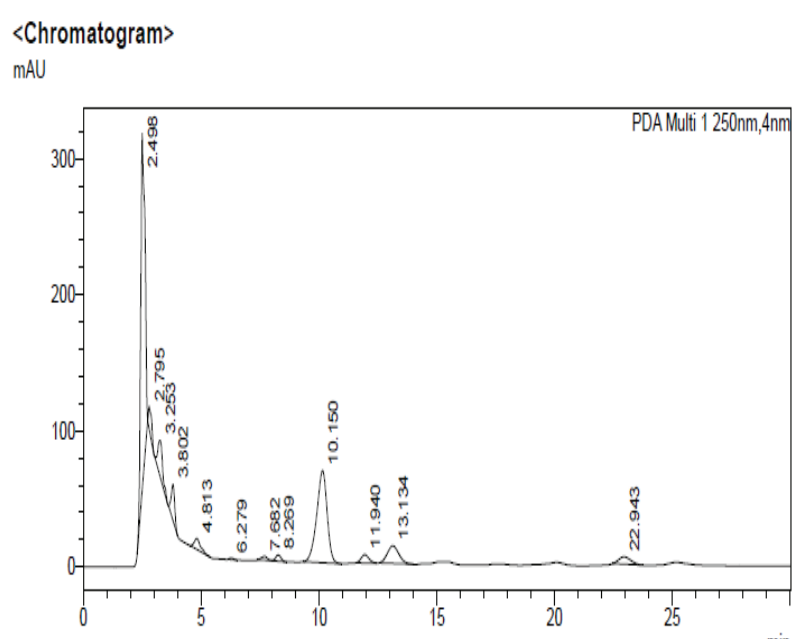

Fig. 2: HPLC chromatogram of Glycyrrhiza glabra DE at $250 \mathrm{~nm}$

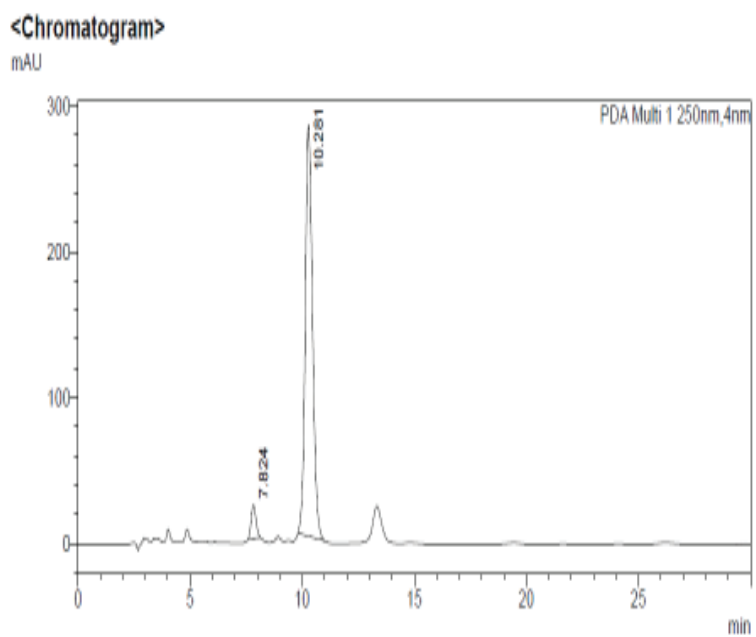

Fig. 3: HPLC chromatogram of Glycyrrhizin at $250 \mathrm{~nm}$

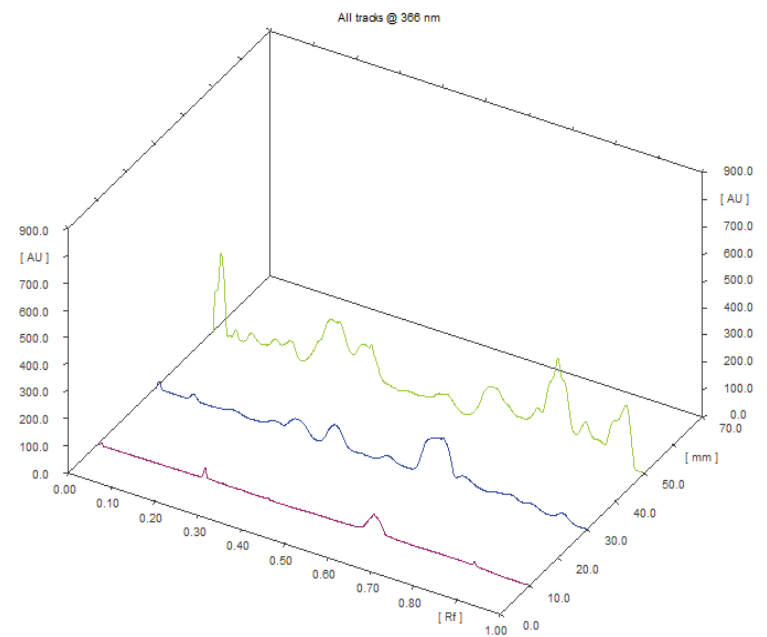

Fig. 4: HPTLC fingerprinting of Piperine, Piper longum DE and Piper longum powder at $366 \mathrm{~nm}$

38.644 which are shown in fig. 8 and fig. 9. Rf Value of Vasicine standard, Adhatoda vasica $\mathrm{DE}$ and Adhatoda vasica powder were found to be 0.65 (fig.10). Physicochemical parameters of Adhatoda vasica dry extract are detailed in Table 5. Adhatoda vasica dry extract contains $2.3 \%$ of Vasicine. Retention time (RT) of Adhatoda vasica dry extract was 5.877 and Vasicine standard was 5.807 which are shown in fig.11 and fig.12. Anti-tubercular activity of Glycyrrhiza glabra DE (Yastimadhu) at $80 \mathrm{mg}$ (fig.13), Piper longum DE (Pippali) at $50 \mathrm{mg}$ (fig.14) and Curcuma longa at

TABLE 3: PHYSICOCHEMICAL EVALUATION OF Piper longum DE

\begin{tabular}{lc}
\hline Parameters & Results \\
\hline Description & $\begin{array}{c}\text { Yellowish-brown color powder } \\
\text { with a characteristic taste }\end{array}$ \\
LOD & $5.89 \%$ \\
pH (1 \% solution) & 3.89 \\
Water Soluble extractive & $76.36 \%$ \\
Alcohol Soluble extractive & $11.51 \%$ \\
Total Ash & $7.51 \%$ \\
Acid insoluble ash & $6.86 \%$ \\
$\%$ Active of Piperine by & $7.0 \%$ \\
HPLC &
\end{tabular}

$\mathrm{DE}=$ Dry extract; $\mathrm{LOD}=\mathrm{Loss}$ on drying; HPLC=High performance liquid chromatography

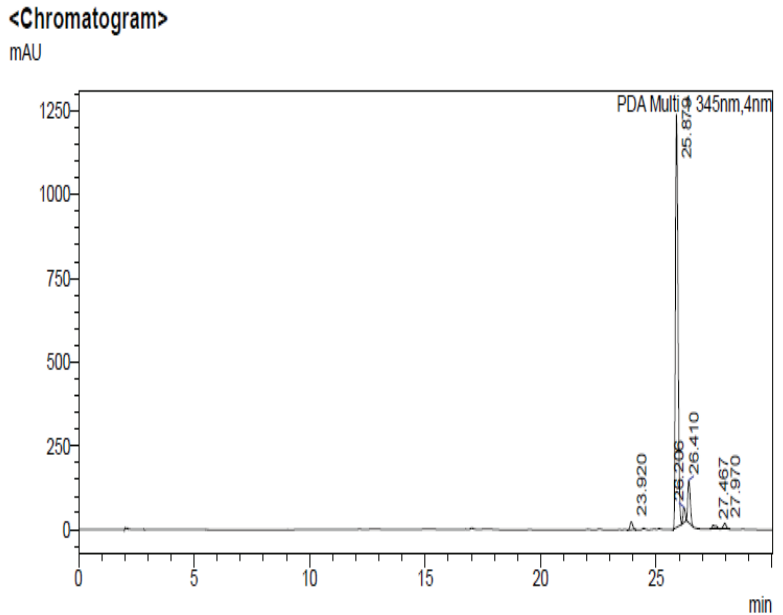

Fig. 5: HPLC chromatogram of Piper longum DE at $345 \mathrm{~nm}$ «Chromatogram》 MAU

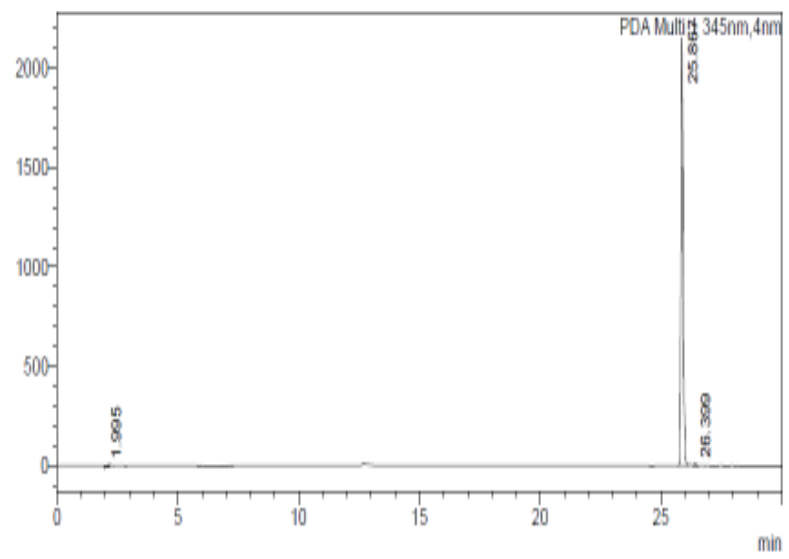

Fig. 6: HPLC chromatogram of Piperine at $345 \mathrm{~nm}$ 


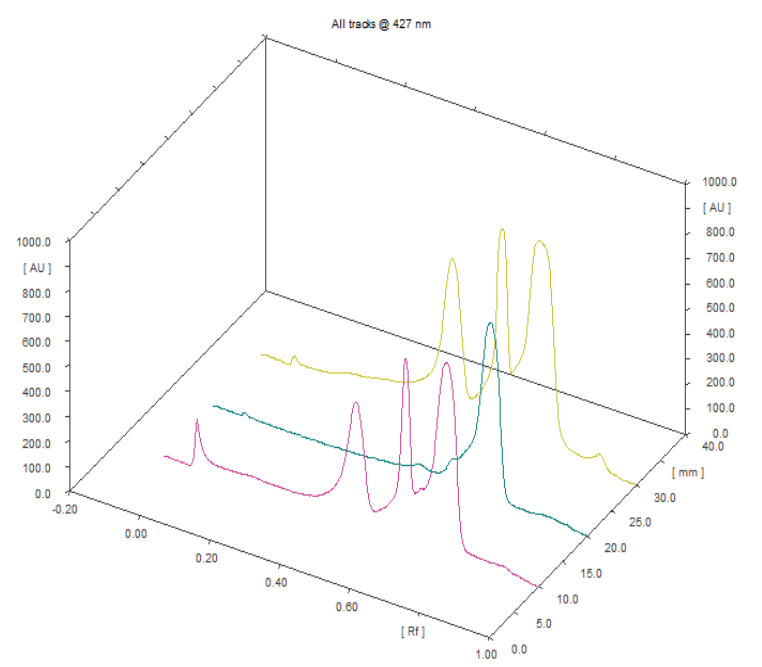

Fig. 7: HPTLC fingerprinting of Curcuma longa DE, Curcumin and Curcuma longa powder at $427 \mathrm{~nm}$

TABLE 4: PHYSICOCHEMICAL EVALUATION OF Curcuma longa DE

\begin{tabular}{lc}
\hline Parameters & Results \\
\hline Description & $\begin{array}{c}\text { Yellow-orange color } \\
\text { fine powder with a } \\
\text { characteristic odor }\end{array}$ \\
LOD & $1.45 \%$ \\
pH (1 \% solution) & 5.10 \\
Water Soluble extractive & $15.05 \%$ \\
Alcohol Soluble extractive & $73.00 \%$ \\
Total Ash & $0.52 \%$ \\
Acid insoluble ash & $0.06 \%$ \\
$\%$ Assay of Curcumin by HPLC & $82.41 \%$ \\
\hline
\end{tabular}

$\mathrm{DE}=$ Dry extract; $\mathrm{LOD}=$ Loss on drying; HPLC=High performance liquid chromatography

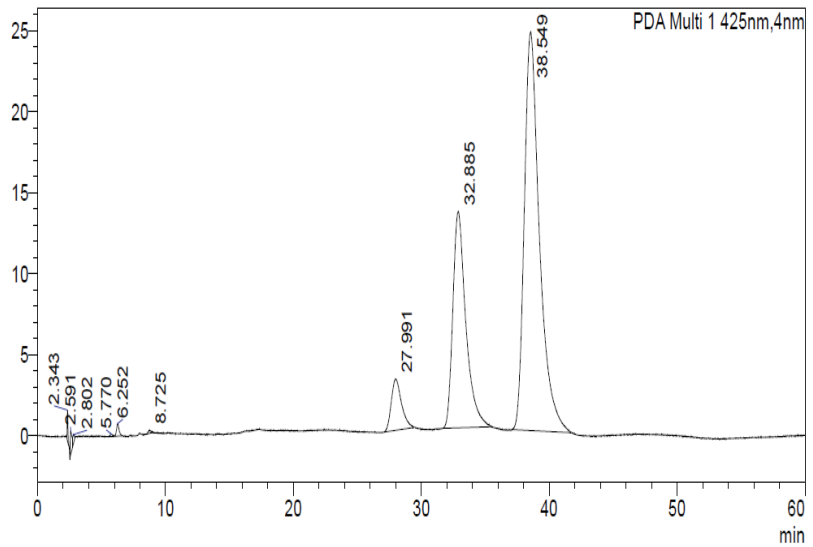

Fig. 8: HPLC chromatogram of Curcuma longa DE at $425 \mathrm{~nm}$

$10 \mathrm{mg}$ (fig.15) shows the maximum zone of inhibition. Adhatoda vasica DE did not show any activity (fig.16).

Above results demonstrated that selected standardized plant extracts have the potential to treat tuberculosis. However, Adhatoda vasica DE did not give any activity against Mycobacterium smegmatis but Ayurvedic literature review and latest scientific publications revealed that Adhatoda vasica is one of the major and common ingredient in Classical formulations which is commonly used for the treatment of "Kshyaroga" (TB) and has a potential role as an anti-tuberculosis drug. A Combination of Adhatoda vasica with other standardized plant extracts may be helpful in symptomatic treatment. The major problem with long-term use of existing allopathic anti-TB drugs are drug resistance and adverse effects. Drugresistant tuberculosis is widespread. Research studies

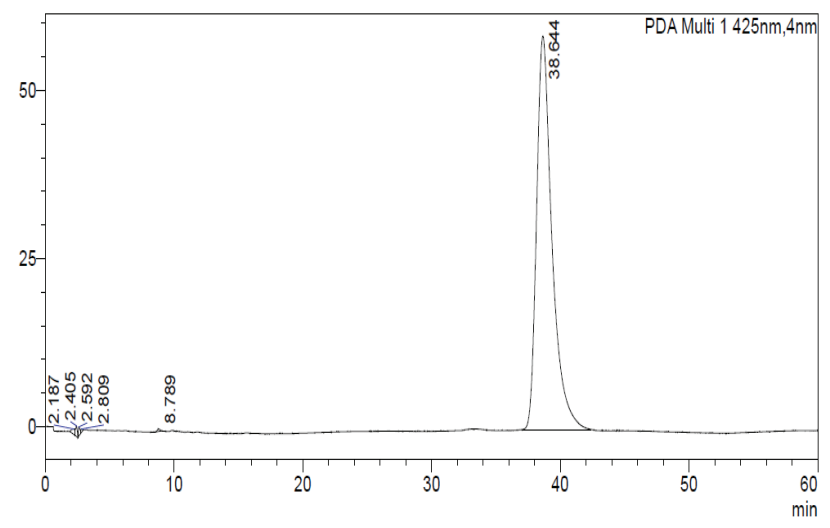

Fig. 9: HPLC chromatogram of Curcumin at $425 \mathrm{~nm}$

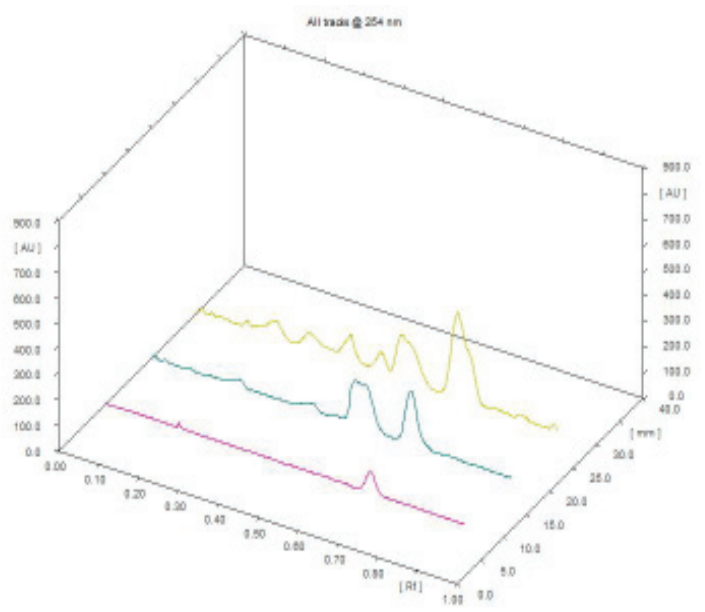

Fig.10: HPTLC fingerprinting of Vasicine, Adhatoda vasica DE and Adhatoda vasica Powder at 254 nm

TABLE 5: PHYSICOCHEMICAL EVALUATION OF Adhatoda vasica DE

\begin{tabular}{lc}
\hline Parameters & Results \\
\hline Description & $\begin{array}{c}\text { Brown color powder with } \\
\text { characteristic odor and } \\
\text { bitter taste }\end{array}$ \\
LOD & $3.52 \%$ \\
pH (1\% solution) & 4.82 \\
Water Soluble extractive & $95.96 \%$ \\
Alcohol Soluble extractive & $38.99 \%$ \\
Total Ash & $6.40 \%$ \\
Acid insoluble ash & $0.34 \%$ \\
$\%$ Active of Vasicine by HPLC & $2.3 \%$ \\
\hline
\end{tabular}

$\mathrm{DE}=$ Dry extract; $\mathrm{LOD}=\mathrm{Loss}$ on drying; HPLC=High performance liquid chromatography 
<Chromatogram>

$\mathrm{mAU}$

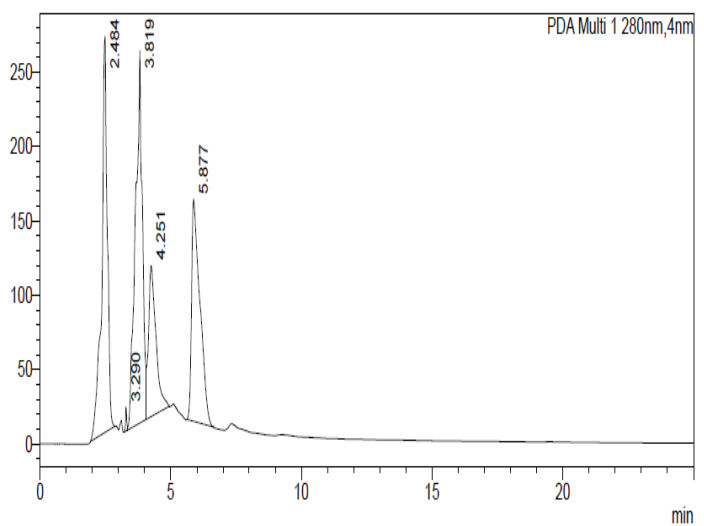

Fig. 11: HPLC chromatogram of Adhatoda vasica DE at $280 \mathrm{~nm}$

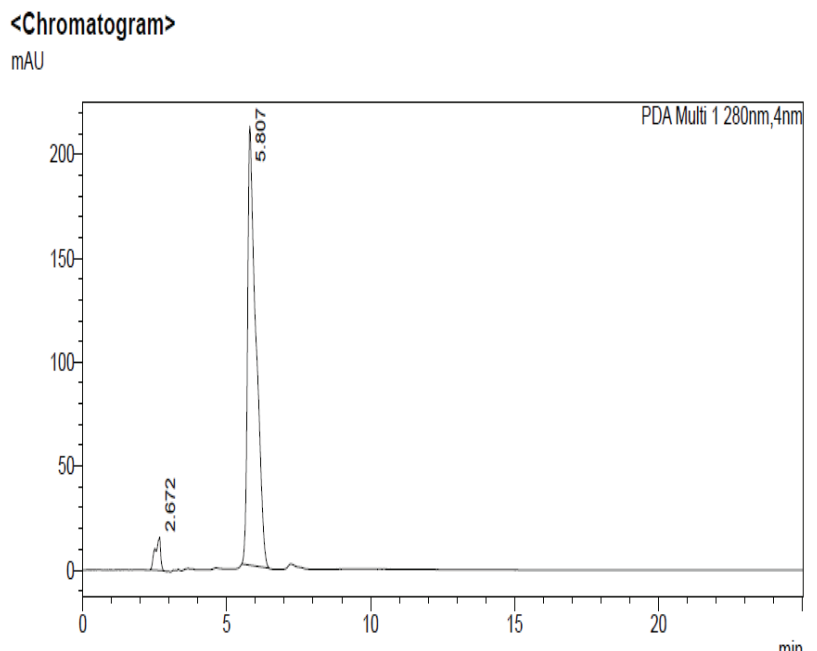

Fig. 12: HPLC Chromatogram of vasicine at $280 \mathrm{~nm}$

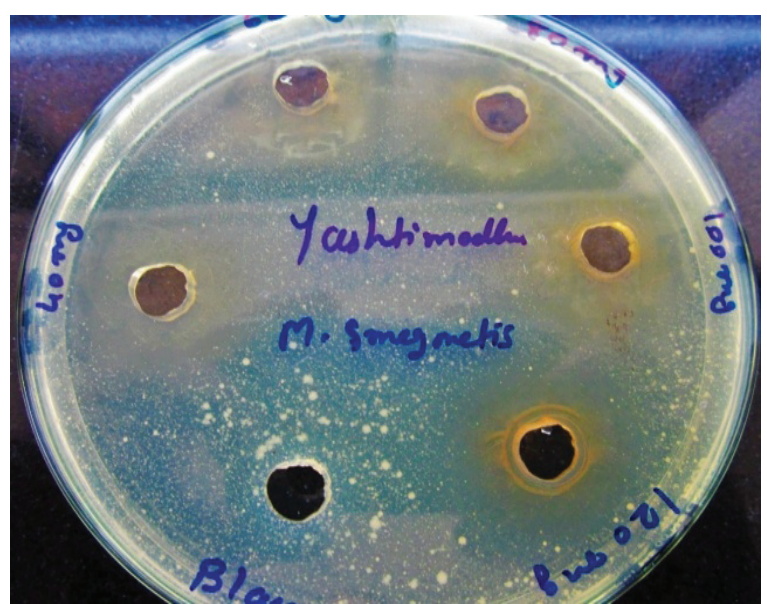

Fig.13: Zone of inhibition (ZOI) of Glycyrrhiza glabra at different doses

have been reported that the main advantage of natural antimicrobial agents is that they do not promote the development of resistance. Various research articles and Ayurvedic literature showed that natural products derived from medicinal plants may play a significant role in the discovery of new anti-TB drugs and can

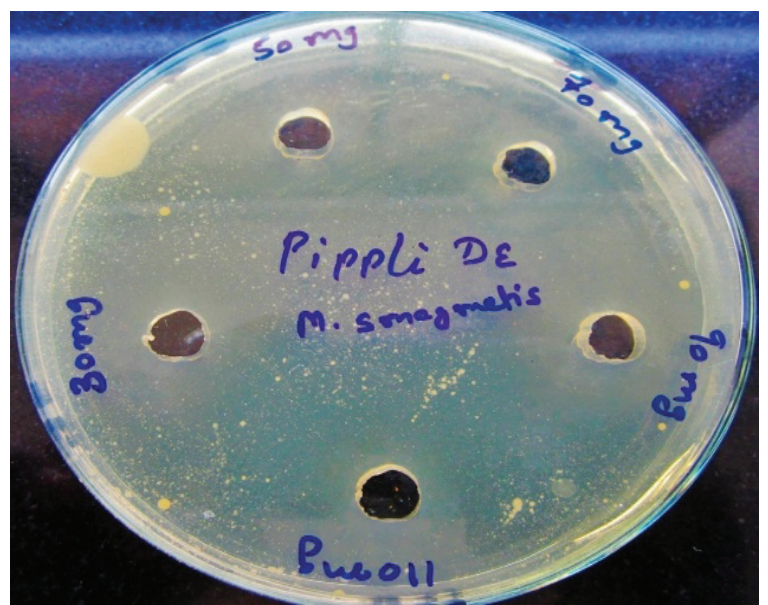

Fig. 14: Zone of inhibition (ZOI) of Piper longum at different doses

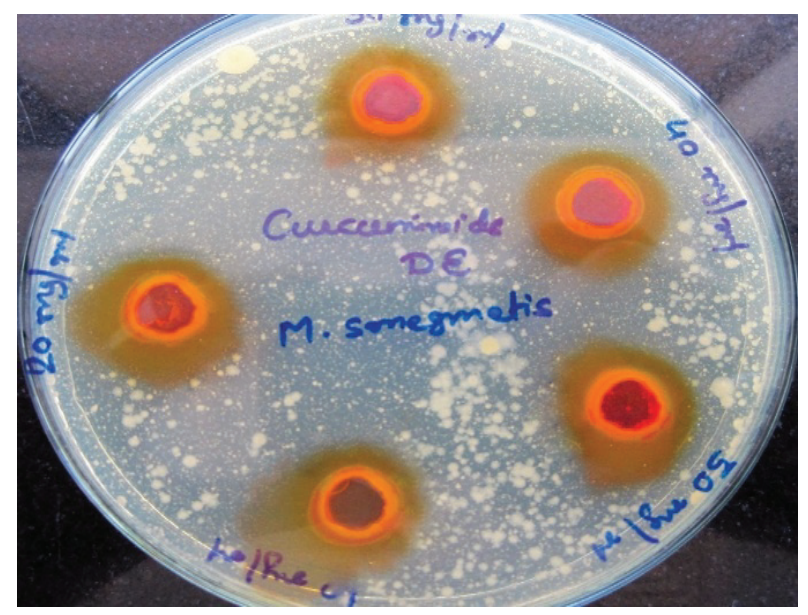

Fig. 15: Zone of inhibition (ZOI) of Curcuma longa at different doses

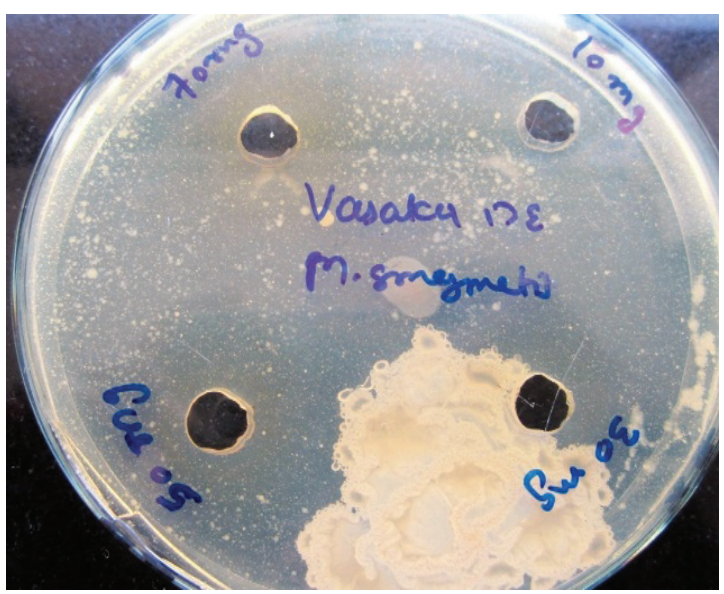

Fig. 16: Zone of inhibition (ZOI) of Adhatoda vasica at different doses

be used as an alternative therapy. The quality control point of view, Identification, Standardization, and Quantification of selected plant extracts are mandatory for the formulation of any dosage form like tablet, capsule, syrup, powder etc. In vitro anti-tuberculosis activity was performed on Mycobacterium smegmatis 
by Agar well diffusion method, the advantage of using this bacterial strain is naturally resistant to isoniazid and rifampin and has the same profile to MDR strains of Mtb. Formulation development is an important criterion for patient compliance and consistent efficacy. So, this study has been further executed in different combinations of plant extracts for formulation of novel dosage form and efficacy and quality parameters will be evaluated for developed polyherbal formulation and present in upcoming publication.

\section{Conflict of interests:}

The authors declare no conflict of interest.

\section{Acknowledgements:}

The authors will grateful to Mr. Vikram Trivedi, (GM of Vasu Research Centre), Mr. Vishal Patel (Department of ADL) and Ms. Mansi Thakker (Department of Microbiology) for their kind encouragement and support.

\section{REFERENCES}

1. Godreuil S, Tazi L, Bañuls AL. Pulmonary tuberculosis and Mycobacterium tuberculosis: modern molecular epidemiology and perspectives. Encyclopedia of infectious diseases: Modern methodologies 2007.

2. Global tuberculosis report. Geneva: WHO 2019.

3. Tortoli E. Microbiological features and clinical relevance of new species of the genus Mycobacterium. Clin Microbiol Rev 2014;27:727-52.

4. Falzon D, Jaramillo E, Schünemann HJ, Arentz M, Bauer $\mathrm{M}$, J Bayona, et al. WHO guidelines for the programmatic management of drug-resistant tuberculosis: 2011 update. Eur Respir J 2011;38:516-28.

5. Ayurvedic Formulary of India, 2nd ed, Part-1. The controller of publications, Delhi, India; 2003.

6. Ayurvedic Formulary of India, 1st ed, Part-3. The controller of publications, Delhi, India; 2011.

7. Ayurvedic Formulary of India, 1st ed, Part-2. The controller of publications, Delhi, India; 2000.

8. Kaur R, Kaur H, Dhindsa AS. Glycyrrhiza glabra: a phytopharmacological review. Int $J$ Pharm Sci Res 2013;4(7):2470.

9. Nandkarni K.M, Nandkarni A.K. Indian Materia Medica. Popular Prakashan, $2^{\text {nd }}$ ed, Vol-I, Mumbai, India; 2013. p. 582.

10. Grover IS, Rai J, Kajal NC, Bhushan B. Effect of liquorice
[Glycyrrhiza glabra linn.] As an adjuvant in newly diagnosed sputum smear-positive patients of pulmonary tuberculosis on directly observed treatment short course (dots) therapy. Chest 2006;130(4):95S.

11. Sharma S, Kumar M, Sharma S, Nargotra A, Koul S, Khan IA. Piperine as an inhibitor of Rv1258c, a putative multidrug efflux pump of Mycobacterium tuberculosis. J Antimicrob Chemother 2010;65(8):1694-701.

12. Alexander A, Qureshi A, Kumari L, Vaishnav P, Sharma $\mathrm{M}$, Saraf $\mathrm{S}$, et al. Role of herbal bioactives as a potential bioavailability enhancer for active pharmaceutical ingredients. Fitoterapia 2014;97:1-4.

13. Vora A, Patel S, Patel K. Role of Risorine in the Treatment of Drug-Susceptible Pulmonary Tuberculosis: A Pilot Study. J Assoc Physicians India 2016;64(11):20-4.

14. Bai X, Oberley-Deegan RE, Bai A, Ovrutsky AR, Kinney $\mathrm{WH}$, Weaver M, et al. Curcumin enhances human macrophage control of Mycobacterium tuberculosis infection. Respirology 2016;21(5):951-7.

15. Kumari B, Kumar T, Kaur V. Hepatoprotective effect of ethanolic extract of Curcuma longa Linn on antitubercular drugs induced hepatotoxicity in albino rats. Int Res J Pharm 2018;9:106-10.

16. Cikrikci S, Mozioglu E, Yilmaz H. Biological activity of curcuminoids isolated from Curcuma longa. Rec Nat Prod 2008;2(1):19-24.

17. Yadav N, Yadav E, Yadav JS. Antimicrobial activity of selected natural products against Gram-positive, Gram-negative and Acid-fast bacterial pathogens. Alt Med Stu 2012;2(1):e13.

18. N. Kumar. Pharmaceutical attributes of Vasa (Adhatoda vasica Linn.) -A review. World J Pharm Res 2016;5:437-55.

19. Nandkarni K.M, Nandkarni A.K. Indian Materia Medica, Popular Prakashan, 2nd ed, Vol-1, Mumbai, India; 2013. p. 40.

20. Indian Pharmacopoeia. The Indian Pharmacopoeia Commission, Ghaziabad, Vol-3, India; 2014. p. 3283.

21. Indian Pharmacopoeia. The Indian Pharmacopoeia Commission, Ghaziabad, Vol-3, India; 2014. p. 3255.

22. Indian Pharmacopoeia. The Indian Pharmacopoeia Commission, Ghaziabad, Vol-3, India; 2014. p. 3222.

23. Indian Pharmacopoeia. The Indian Pharmacopoeia Commission, Ghaziabad, Vol-3, India; 2014. p .3279.

24. The Ayurvedic Pharmacopoeia of India. Part-I, Vol-8, Government of India, Department of Ayurveda, Yoga \& Naturopathy, Unani, Siddha \& Homeopathy (Ayush); 2011.

25. Wichitnithad W, Jongaroonngamsang N, Pummangura S, Rojsitthisak P. A simple isocratic HPLC method for the simultaneous determination of curcuminoids in commercial turmeric extracts. Phytochem Anal 2009;20(4):314-9. 